\title{
A Comparative Study for Reactive (Blue 19) Dye Adsorption Onto Polyaniline Prepared by Both Aps and Catalyzed $\mathrm{H}_{2} \mathrm{O}_{2}$ Pathways.
}

\author{
A.G. Gadallah, M.A. Abd El-Ghaffar", N.N. Ibiari", S.S. Younis ${ }^{* * *}$ \\ and O.F. Abd El-Salam ** \\ Department of Chemical Engineering, "Department of Polymers \\ and Pigments, Natiomal Research Centre, and ${ }^{* *}$ Department of \\ Chemical Engineering, Faculty of Engineering, Cairo \\ University, Cairo, Egypt.
}

\begin{abstract}
T N THE present study, polyaniline (PANI), chemically synthesized 1 using ammonium peroxydisulfate [APS] and by catalyzed hydrogen peroxide $\left(\mathrm{H}_{2} \mathrm{O}_{2}\right)$, was evaluated as adsorbents for reactive (blue 19) dye. Experiments were conducted in batch mode where some parameters affecting the adsorption capacity such as contact time and concentration of dye have been investigated. An atomic absorption spectroscopy method was used for the measurement of dye contents. Adsorption equilibrium was achieved within $60 \mathrm{~min}$ and the adsorption capacity $\left(\mathrm{q}_{\mathrm{e}}\right)$ was $350 \mathrm{mg} / \mathrm{gm}$ (PANI) under the optimal conditions. Adsorption equilibrium studies were carried out and showed that adsorption follows Freundlish model. The adsorption kinetics was best described by pseudo-second-order model. The results indicated that PANI, synthesized by catalyzed hydrogen peroxide $\left(\mathrm{H}_{2} \mathrm{O}_{2}\right)$ can be used as a novel effective adsorbent material for the removal of the tested reactive dye with higher adsorption capacity than PANI prepared by APS.
\end{abstract}

Keywords: Conductive polymers, Polyaniline, Reactive (blue 19) dye, Sonochemical polymerization, Dye adsorption

Polyaniline is the most important and widely used type of electrically conducting polymers which has shown good stability along with simplicity of preparation ${ }^{(1)}$. Polyaniline (PANI) exists in a variety of forms that differ in chemical and physical properties. The most common green protonated emeraldine has conductivity on a semiconductor level of the order of $1-10 \mathrm{~S} / \mathrm{cm}$ which is many orders of magnitude higher than that of common polymers $\left(<10^{-9} \mathrm{~S} / \mathrm{cm}\right)$. Protonated PANI, (e.g., PANI hydrochloride) converts to a nonconducting blue emeraldine base when treated with ammonium hydroxide ${ }^{(2)}$. As shown in Fig. 1, the common synthetic process of PANI depends on oxidation of aniline hydrochloride (solution of aniline in hydrochloric acid) with APS to yield conducting polyaniline (emeraldine salt), see Fig. $2^{(3-9)}$. APS is a strong oxidant, and the polymerization of aniline is an exothermal reaction, so the reaction heat is difficult to control, leading to an agglomeration of the product and wide molecular weight distribution which worst the mechanical properties of PANI and reduce chelating activity on its surface. ${ }^{(9,10)}$ 
In our previous studies we have reported the synthesis and characterization of PANI and its derivatives via chemical oxidation pathway using APS. The study included doping agent modification ${ }^{(11,12)}$, synthesis of PANI composites with different materials for specific applications as corrosion inhibitor for paint applications ${ }^{(13-15)}$, antioxidant additives for rubber industry ${ }^{(16,17)}$ and conducting nano-composites ${ }^{(18,19)}$.

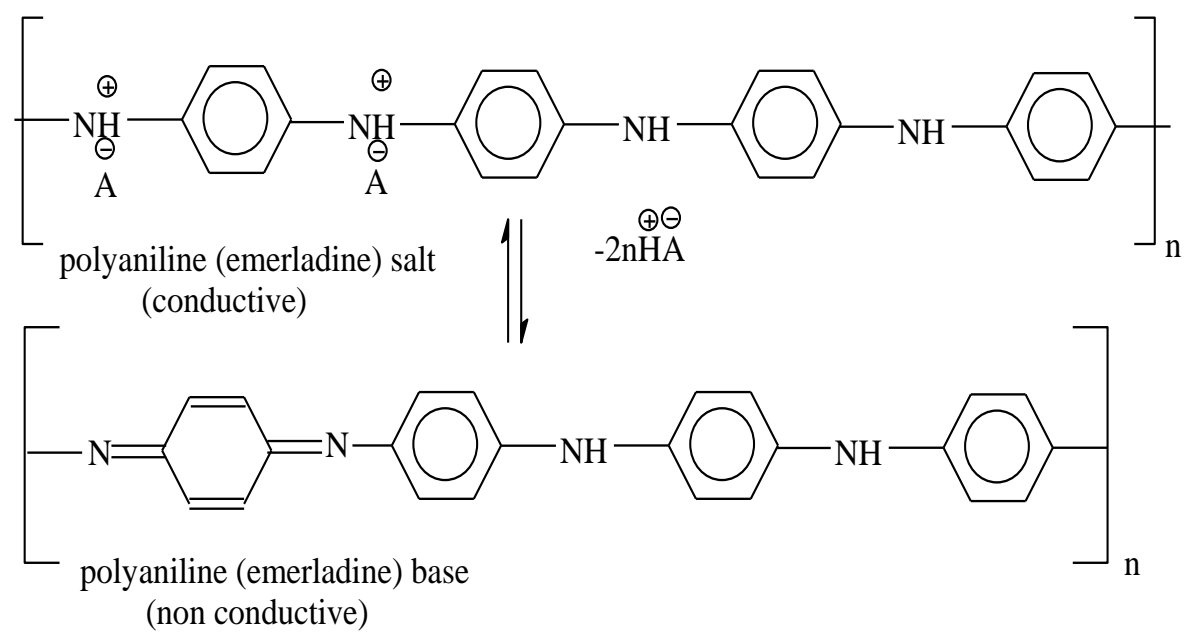

Fig. 1. Different forms of polyaniline Source: (J. STEJSKAL et al [6].) .

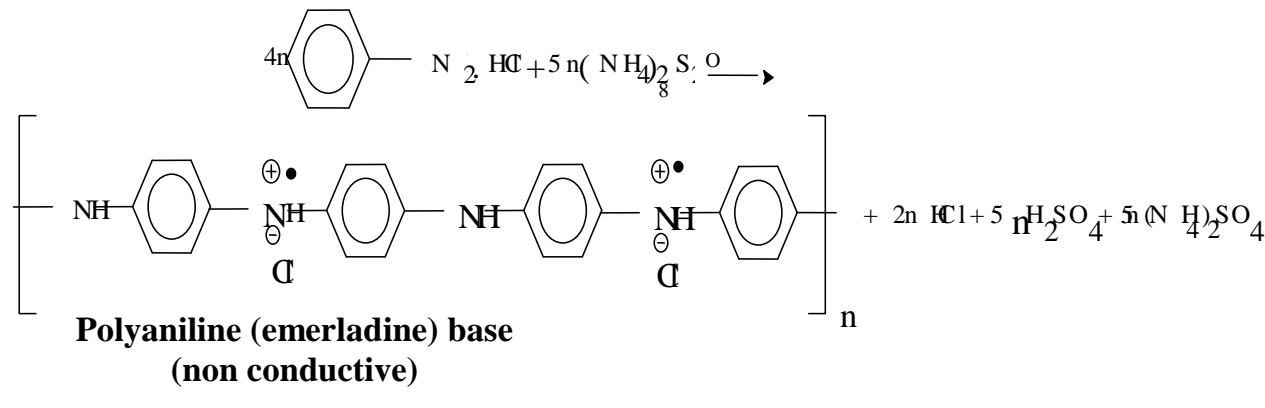

Fig. 2. Oxidation of aniline hydrochloride with APS Source: (J. STEJSKAL et al [7].)

$\mathrm{H}_{2} \mathrm{O}_{2}$ has been reported as an excellent oxidant for aniline polymerization because it enhances the particle size distribution and morphology of polyaniline and yields water as byproduct which greatly simplifies the industrial process and enables recycling of reaction medium because it does not contain any harmful components to aniline polymerization ${ }^{(20)}$. But when $\mathrm{H}_{2} \mathrm{O}_{2}$ alone is used as oxidant, the reaction rate is extremely low. In order to increase the rate of Egypt. J. Text. Polym. Sci. Technol. 14, No. 2 (2010) 
reaction, the reaction may be catalyzed by using of ultrasonic waves and slight ratios of $\mathrm{FeCl}_{3}$ catalyst which drastically increase the yield and rate of reaction to acceptable value for applications ${ }^{(20-25)}$. Recently, "polyaniline" and its composites have become under investigation as exciting new absorbing materials for water contaminants like dyes and toxic heavy metals due to the active sits on PANI surface ${ }^{(26-30)}$.

The ultimate goal of this study is to investigate and compare the effect of PANI prepared by both chemical oxidations using APS as well as $\mathrm{H}_{2} \mathrm{O}_{2}$ catalyzed by ultrasonic waves and $\mathrm{FeCl}_{3}$ on the adsorption potency of reactive (blue 19) dye

\section{Experimental}

Materials

Commercial grade aniline $\left(\mathrm{C}_{6} \mathrm{H}_{5} \mathrm{NH}_{2}\right)$ [Adwic Co. Egypt] was purified by distillation at $180{ }^{\circ} \mathrm{C}$. Commercial Reactive (blue 19) dye $\left(\mathrm{C}_{23} \mathrm{H}_{13} \mathrm{ClN}_{8} \mathrm{Na}_{2} \mathrm{O}_{10} \mathrm{~S}_{2}\right)$ was supplied by Al-Alamia Co. for Modern Weaving and Textiles, Egypt. Ammonium peroxydisulfate $\left[\left(\mathrm{NH}_{4}\right)_{2} \mathrm{~S}_{2} \mathrm{O}_{8}\right]$ and Dimethyl formamide (DMF), were purchased from Aldrich-Sigma Company, Germany, and used as received. Analytical grades of $\mathrm{H}_{2} \mathrm{O}_{2}(30 \%)$ and $\mathrm{HCl}(36 \%)$ were purchased from Adwic Co. Egypt. $\mathrm{FeCl}_{3}$ salt was purchased from $\mathrm{BDH}$ Chemical ltd, England.

\section{Methods}

Preparation of PANI

Two samples of polyaniline were prepared: (P1) for PANI prepared using APS as initiator and (P2) for PANI prepared by using catalyzed $\mathrm{H}_{2} \mathrm{O}_{2}$ as initiator according to the following methods:-

Preparation of $(P 1): 5 \mathrm{ml}(0.55 \mathrm{~mol})$ of freshly distilled aniline was dissolved in $100 \mathrm{ml}$ of $1 \mathrm{M} \mathrm{HCl}$ solution and stirred for $10 \mathrm{~min}$ to ensure the homogeneity of the mixture. $12.55 \mathrm{gm}(0.55 \mathrm{~mol})$ of APS salt (Aniline : APS; 1:1 molar ratio) was dissolved in $100 \mathrm{ml}$ distilled water and added dropwise to the aniline - $\mathrm{HCl}$ solution while stirring at room temperature for $1 \mathrm{hr}$ The precipitated dark green powder of PANI was filtered and washed by hot bidistilled water and acetone till the filtrate becomes colorless. The washed precipitate was dried at $60{ }^{\circ} \mathrm{C}$ overnight and ground to fine powder.

Preparation of (P2): $5 \mathrm{ml}(0.55 \mathrm{~mol})$ of freshly distilled aniline was dissolved in $100 \mathrm{ml}$ of $1 \mathrm{M} \mathrm{HCl}$ solution and stirred for $10 \mathrm{~min}$ Droplets of $\mathrm{FeCl}_{3}$ solution as catalyst was added to the solution followed by droplets of $\mathrm{H}_{2} \mathrm{O}_{2}$ solution (30\%) for reaction initiation where the molar ratio of aniline: $\mathrm{H}_{2} \mathrm{O}_{2}: \mathrm{FeCl}_{3}$ is equal to 1:1:0.002 respectively. Then the reaction mixture was sonicated for $3 \mathrm{hr}$ in ultrasonic bath under frequency of $30 \mathrm{kHz}$. Finally the reaction product was collected and washed as previously described in (P1). 
Adsorption studies

Adsorption experiments were performed in batch equilibrium mode. All experiments were carried out by placing $0.05 \mathrm{~g}(\mathrm{P} 1)$ and $(\mathrm{P} 2)$ into two conical flasks, each has $50 \mathrm{ml}$ of dye solutions. The mixtures were agitated at $200 \mathrm{rpm}$ at room temperature for different contact time and dye concentration. Then the solution was separated by filtration and a sample of the filtrate was analyzed to determine the equilibrium concentration of dye after adsorption. The adsorbed amounts of dye were calculated using the equation:

$$
\mathrm{q}_{\mathrm{e}}=\left(\mathrm{C}_{\mathrm{o}}-\mathrm{C}_{\mathrm{e}}\right) \mathrm{V} / \mathrm{m}
$$

Where $\mathrm{C}_{\mathrm{o}}$ and $\mathrm{C}_{\mathrm{e}}$ are the initial and equilibrium concentrations of dye ( $\mathrm{mg} / \mathrm{L}$ ), $\mathrm{m}$ is the mass of PANI $(\mathrm{g})$, and $\mathrm{V}$ is the volume of solution $(\mathrm{L})$.

Characterization

-Molecular weight $\left(\mathrm{M}_{\mathrm{w}}\right)$ of PANI was measured by gel permeation chromatography (GPC) technique using polystyrene basis [Model: Infinity-1220, Agilant, Germany] and Dimethyl Formamide (DMF) as solvent for PANI. To ensure complete solubility of PANI in DMF, samples were firstly transformed to non conductive emeraldine base form by stirring in $1 \mathrm{M} \mathrm{NH}_{4} \mathrm{OH}$ for $1 \mathrm{hr}$, then washed by distilled water and dried at $60{ }^{\circ} \mathrm{C}$ overnight ${ }^{(9)}$

- Electrical conductivity of the PANI was measured on pressed pellets employing a standard two-probe method [Model: HY3020E- MASTECH DC POWER SUPPLY, USA].

-Particle size and morphology were evaluated by transmission electron microscope (TEM) [Model EM10; Zeiss, Germany].

- Equilibrium dye concentrations were analyzed by spectrophotometer [Model: $\mathrm{HACH}$ (DR2800)] at $540 \mathrm{~nm}$ maximum wavelength for Blue 19 reactive dye as resulted from experimental work.

\section{Results and Discussion}

\section{Characteristics of PANI}

Table 1 shows a comparison between molecular weight, DC conductivity for (P1) and (P2). The results showed that PANI which was prepared by catalyzed $\mathrm{H}_{2} \mathrm{O}_{2}$ (P2) has higher molecular weight, lower polydespersity index (D) and higher DC conductivity than that prepared using APS (P1). The higher molecular weight of (P2) may be attributed to slower reaction rate of catalyzed $\mathrm{H}_{2} \mathrm{O}_{2}$ than APS as initiator which delays and reduces the number of free radicals in the initiation step compared to propagation of polymer chain ${ }^{(26)}$

DC conductivity of (P2) was increased by the catalytic effect of $\mathrm{FeCl}_{3}$ combined with ultrasonic waves as it enhances the doping process of PANI prepared by $\mathrm{H}_{2} \mathrm{O}_{2}{ }^{(27,28)}$. The addition of $\mathrm{FeCl}_{3}$ in presence of ultrasonic waves 
lowers the formation of by-products during the polymerization reaction and increases the polarity of PANI due to good distribution of $\mathrm{Fe}+3$ ions in the medium by the effect of ultrasonic waves ${ }^{(29,30)}$. The morphological properties of the prepared polyaniline were clarified via TEM analysis as shown in Fig. 3. It is clearly seen that $(\mathrm{P} 2)$ has a uniform nano-porous structure in reverse to (P1) which has a non uniform particle size due to particles agglomeration during the aniline polymerization with APS. The nano porous structure of (P2) may be attributed to the effect of micro cavities which are generated and collapsed during ultrasonic waves in solution, Fig. 4. The collapse of cavities yields severe conditions of pressure and temperature $(1000 \mathrm{bar}, 3000 \mathrm{~K})$ in thousands of hot spots inside the solution without affecting the overall conditions of solution systems ${ }^{(30)}$.
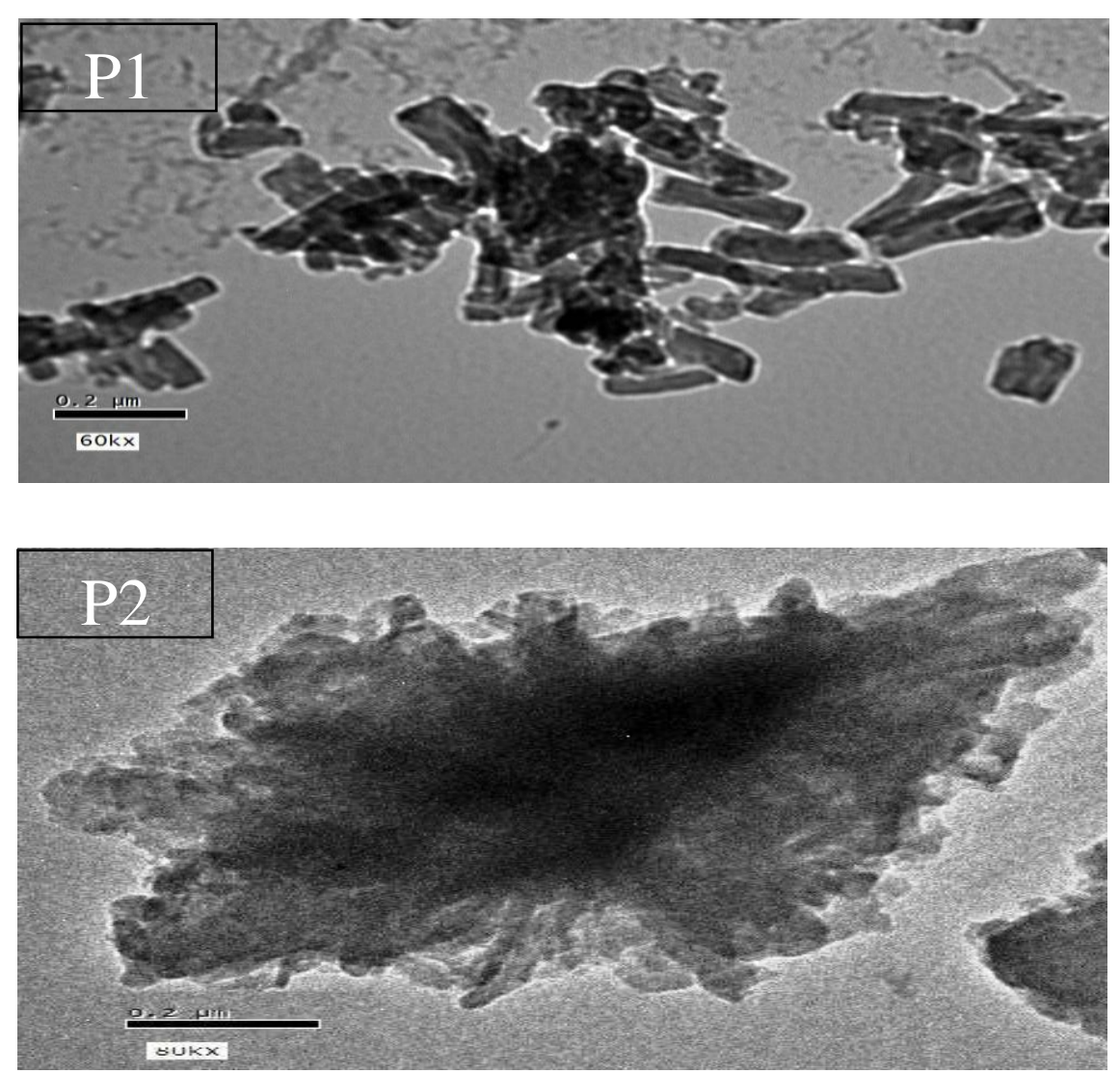

Fig. 3. TEM images for PANI prepared by APS (P1) and catalyzed $\mathrm{H}_{2} \mathrm{O}_{2}(\mathrm{P2})$. 
Sound waves

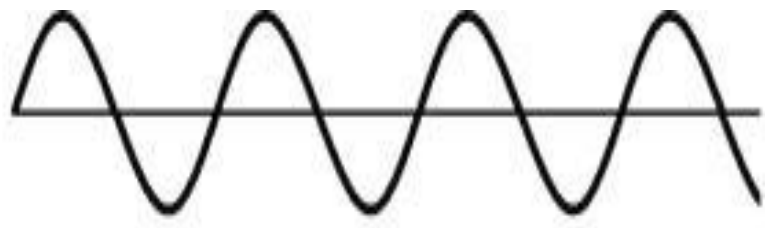

Pressure waves

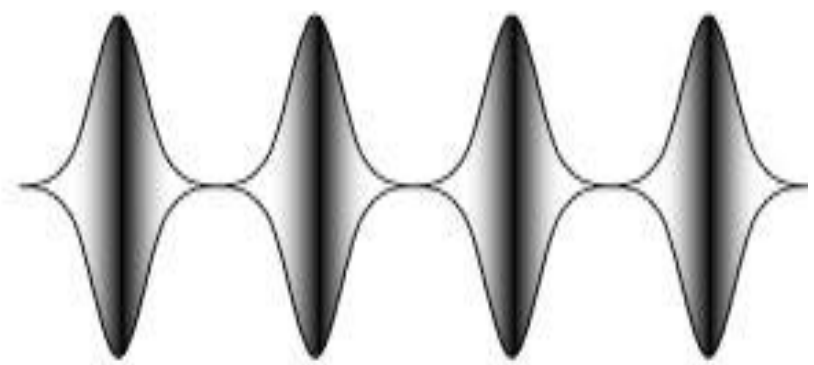

Cavitation bubble growth and collapse

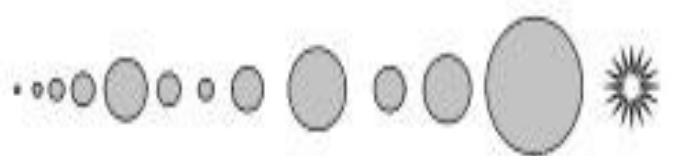

Fig. 4. The growth and collapse of cavitations bubbles. (Source: H.F. Mark et al. [23]).

TABLE 1. Characteristics of PANI prepared by different methods .

\begin{tabular}{|c|c|c|}
\hline \multirow{2}{*}{ Average Molecular weight $\left(\mathrm{M}_{\mathrm{w}}\right)$} & $(\mathbf{P 1})$ & $(\mathbf{P 2})$ \\
\cline { 2 - 3 } & 40650 & 62487 \\
\hline Number Molecular weight $\left(\mathrm{M}_{\mathrm{n}}\right)$ & 34475 & 59164 \\
\hline Polydespersity Index $(\mathrm{D})$ & 1.17 & 1.05 \\
\hline DC conductivity $(\sigma)[\mathrm{S} / \mathrm{cm}]$ & 1.12 & 1.57 \\
\hline
\end{tabular}

\section{Adsorption studies}

Determination of optimum adsorption time

The adsorption kinetics was conducted to determine the optimum adsorption time for the adsorption of dye onto synthesized PANI. Fig. 5 shows the effect of contact time on the adsorption of dye onto (P1) and (P2). The adsorption capacity increases rapidly during the initial adsorption stage and then continues at a relatively slow speed reaching equilibrium stage after $60 \mathrm{~min}$. The results show firstly that, the adsorption occurs on the surface of PANI, so the adsorption rate is fast. After the surface is saturated, the adsorption gradually goes through 
the inner part of PANI via the diffusion of dye onto the polymer matrix where the repulsion between adsorbate molecules, leading to a lower rat ${ }^{(28,29)}$. It is also clearly seen that, the adsorption rate for (P2) is higher than (P1) due to the porous structure of the particles $(\mathrm{P} 2)$ as previously revealed in TEM analysis.

Determination of maximum adsorption capacity $\left(q_{m}\right)$

Figure 6 compares the adsorption isotherms of dye onto (P1) and (P2). The results show that the adsorption capacity of dye increases with concentration till it reaches a maximum value $\left(\mathrm{q}_{\mathrm{m}}\right)$ which does not change by further increase in concentration. This may be attributed to the extent of a driving force of concentration gradients with the increase of dye concentration. The adsorption isotherm shows that the maximum adsorption capacity for (P1) was about 250 $\mathrm{mg} / \mathrm{g}$ while it increased to about $350 \mathrm{mg} / \mathrm{g}$ for (P2). This could be attributed to the increasing of molecular weight and doping efficiency of polymer, which increase the length of chain and number of active sites thereby enhancing the conductivity and binding effect of polymer surface. This interpretation is in accordance with Maloney et al. assumption ${ }^{(30)}$ who reported that adsorption capacity of polyaniline is mainly depending on the number of active sites on the polymer chain (amine and imine groups), the surface area of the polymer and extent of interaction with dye molecules.

Kinetics modeling study

The study of adsorption dynamics describes the solute uptake which controls the residence time of adsorbate uptake at the solid/solution interface. In this section, the results of the kinetics of dye ions adsorbed from aqueous solutions onto prepared polyaniline by different methods, as illustrated in Fig. 5 were analyzed using pseudo first-order, pseudo second-order and Elovich models, respectively as follow ${ }^{(31)}$ :

i) Pseudo-first-order equation:

$\log \left(\mathrm{q}_{\mathrm{e}}-\mathrm{q}_{\mathrm{t}}\right)=\log \mathrm{q}_{\mathrm{e}}-\left(\mathrm{k}_{1}\right)(\mathrm{t}) /(2.303)$

ii) Intraparticle diffusion equation:

$\mathrm{q}_{\mathrm{t}}=\mathrm{k}_{\mathrm{i}} \mathrm{t}^{0.5}+\mathrm{C}$

iii) Elovich's equation:

$\mathrm{q}_{\mathrm{t}}=\mathrm{b}+\mathrm{a} \ln \mathrm{t}$

Where qe and qt are the amounts of dye adsorbed $(\mathrm{mg} / \mathrm{l})$ at equilibrium and at time $\mathrm{t}(\mathrm{min})$, and $\mathrm{t}$ is the adsorption time $(\mathrm{min})$. The other parameters are different kinetic constants, which can be determined by regression of the experimental data. The validities of these four kinetic models are checked and depicted in Fig. 7. The corresponding kinetic parameters and the correlation coefficients are summarized in Table 2. The conformity between experimental data and each model predicted values was expressed by the correlation coefficient $\left(\mathrm{R}^{2}\right)$. A relatively high $\mathrm{R} 2$ values indicates that the model successfully describes the kinetics of metal ion sorption. 


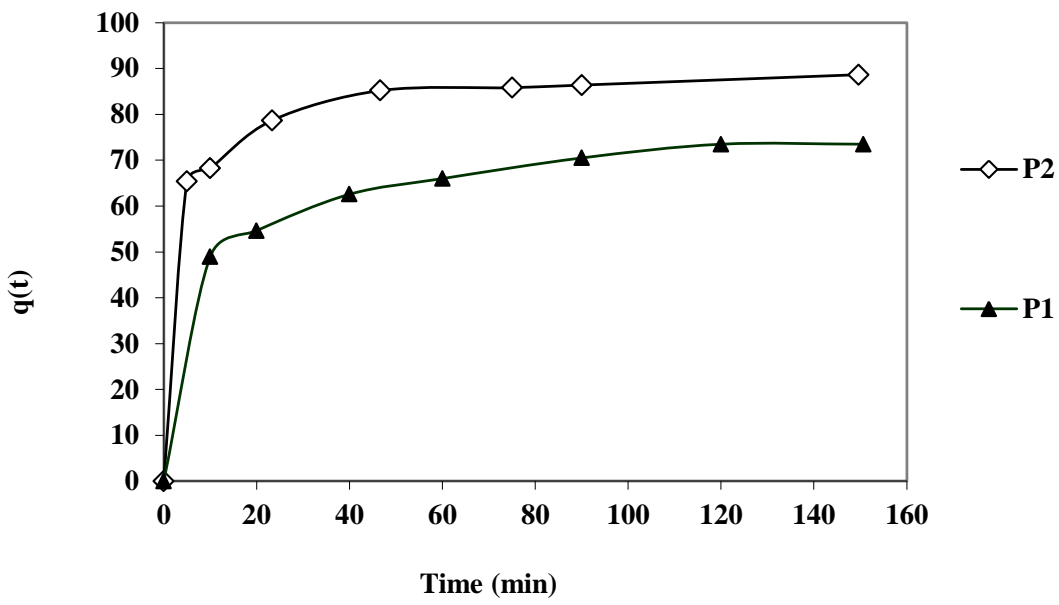

Fig. 5. Reactive blue 19 adsorption kineties on polayaniline prepared by different methods, $C_{\circ}=100 \mathrm{mg} / \mathrm{lit}$.

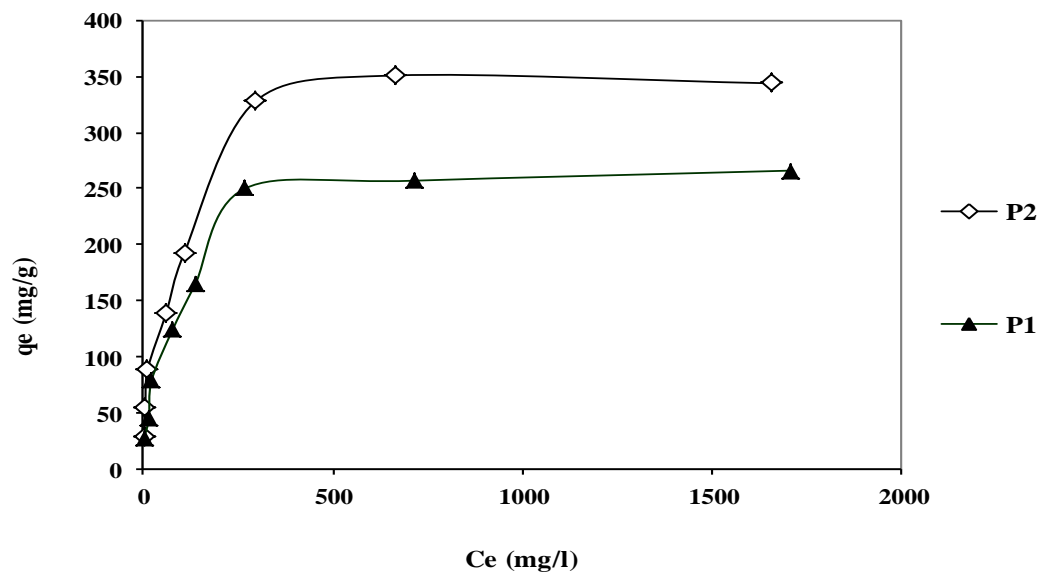

Fig. 6. Adsorption isotherm for blue K-BR dye at polyaniline prepared at different conditions 
A COMPARATIVE STUDY FOR REACTIVE (BLUE 19) DYE ADSORPTION... 105
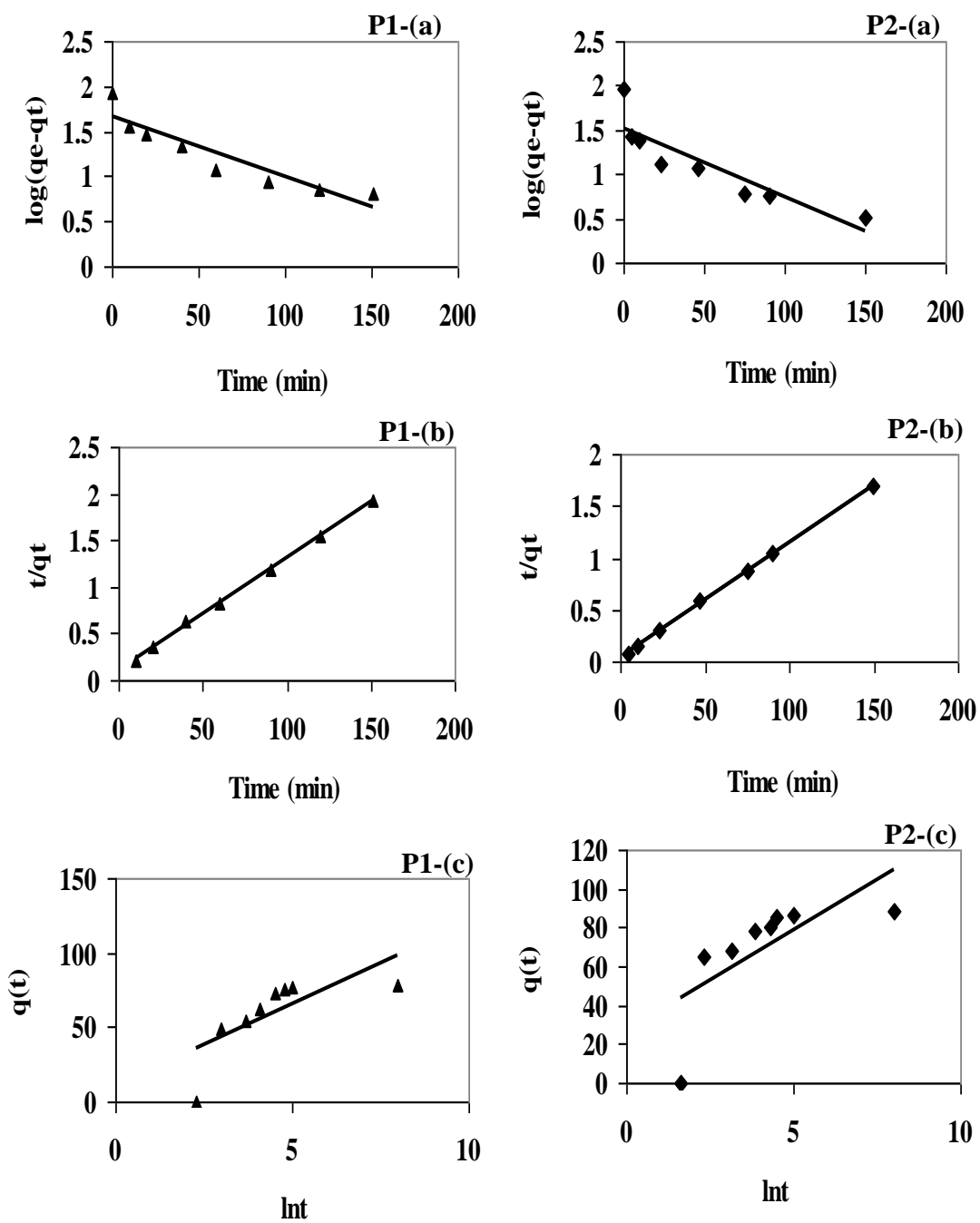

Fig. 7. Adsorption kinetics of Blue 19 reactive dye onto PANI prepared by APS (P1) and catalyzed $\mathrm{H}_{2} \mathrm{O}_{2}$ (P2): (a) pseudo-first-order, (b) pseudo-second-order, (C) Elovich models. 
TABLE 2. Kinetics parameters for reactive (blue 19) dye adsorption on PANI prepared by different methods .

\begin{tabular}{|c|c|c|}
\hline . & (P1) & (P2) \\
\hline \multicolumn{3}{|c|}{ Pseudo-first-order } \\
\hline $\mathrm{k}_{1}\left(\min ^{-1}\right)$ & 0.015 & 0.018 \\
\hline $\mathrm{q}_{\mathrm{e}, \mathrm{cal}}\left(\mathrm{mg} \mathrm{g}^{-1}\right)$ & 40 & 33.01 \\
\hline $\mathrm{q}_{\mathrm{e}, \exp }\left(\mathrm{mg} \mathrm{g}^{-1}\right)$ & 65 & 85 \\
\hline$R^{2}$ & 0.81 & 0.78 \\
\hline \multicolumn{3}{|c|}{ Pseudo-second-order } \\
\hline $\mathrm{k}_{2}\left(\mathrm{gmg}^{-1} \min ^{-1}\right)$ & 0.00125 & 0.00318 \\
\hline $\mathrm{q}_{\mathrm{e}, \mathrm{cal}}\left(\mathrm{mg} \mathrm{g}^{-1}\right)$ & 70.333 & 90.09 \\
\hline$R^{2}$ & 0.9987 & 0.9994 \\
\hline \multicolumn{3}{|l|}{ Elovich } \\
\hline $\mathrm{a}$ & 9.597 & 10.44 \\
\hline $\mathrm{B}$ & 9.597 & 26.47 \\
\hline $\mathrm{R}^{2}$ & 0.529 & 0.487 \\
\hline
\end{tabular}

Based on linear regression $\left(\mathrm{R}^{2}\right)$ values, the adsorption kinetics of dye onto $(\mathrm{P} 1)$ and $(\mathrm{P} 2)$ could be described well $\left(\mathrm{R}^{2}\right.$ near to 1$)$ by pseudo-second order model where the $\mathrm{q}_{\mathrm{e}, \mathrm{cal}}$ value from pseudo-second order model agrees very well with the $\mathrm{q}_{\mathrm{e}, \exp }$ value which indicates the high adsorption capacity for (P2 )and (P1). Also the over all rate constant of each sorbent appears to be controlled by physical adsorption interaction on PANI surface as indicated by low linear regression $\left(\mathrm{R}^{2}\right)$ value of Elovich model.

\section{Adsorption isotherm models study}

Langmuir, Freundlich, and Temkin models were selected to investigate and compare the adsorption behavior of dye onto (P1) and (P2) polymers. The Langmuir isotherm is commonly used model for monolayer adsorption process where it assumes that the adsorption occurs at specific homogeneous sites on the adsorbent as represented by equation $(6)^{(31)}$ :

$\mathrm{C}_{\mathrm{e}} / \mathrm{q}_{\mathrm{e}}=1 / \mathrm{bq}_{\mathrm{m}}+\mathrm{C}_{\mathrm{e}} / \mathrm{q}_{\mathrm{m}}$

Where the constant $b$ is related to the energy of adsorption $(\mathrm{L} / \mathrm{mg})$ and $\mathrm{q}_{\mathrm{m}}$ is the Langmuir monomolecular adsorption capacity $(\mathrm{mg} / \mathrm{g})$. The value of constant $\mathrm{b}$ is also used for determination of dimensionless constant $\left(\mathrm{R}_{\mathrm{L}}\right)$ according to equation (7):

$\mathrm{R}_{\mathrm{L}}=1 /\left(1+\mathrm{bC} \mathrm{C}_{\mathrm{o}}\right)$

Where $C_{0}(\mathrm{mg} / \mathrm{L})$ is the initial dye concentration. From equation (7), the adsorption is favorable in the values of $\mathrm{R}_{\mathrm{L}}$ lies between 0 and 1 .

The Freundlich isotherm ${ }^{(31)}$ describes the multilayer physical adsorption systems and assumes that the adsorption process takes place on heterogeneous Egypt. J. Text. Polym. Sci. Technol. 14, No. 2 (2010) 
surfaces and adsorption capacity is related to the concentration of dye at equilibrium according to equation $(8)^{(22)}$ :

$\log \mathrm{q}_{\mathrm{e}}=\log \mathrm{K}_{\mathrm{f}}+(1 / \mathrm{n}) \log \mathrm{C}_{\mathrm{e}}$

Where $K_{f}(\mathrm{mg} / \mathrm{g})$ is roughly an indicator of the adsorption capacity and $1 / \mathrm{n}$ is the adsorption intensity.

The Temkin adsorption model [equation (9)], considers the chemisorption of an adsorbate onto the adsorbent. This model assumes that the adsorption is characterized by a uniform distribution of binding energies related to chemical interaction on the surface ${ }^{(32)}$ :

$$
\mathrm{q}_{\mathrm{e}}=\mathrm{A}+\mathrm{B} \log \mathrm{C}_{\mathrm{e}}
$$

Where A and B are Termkin constants.

Figure 8 shows the application of the mentioned models in dye adsorption onto (P1) and (P2) polymers. Table 3 summarizes linear regression $\left(\mathrm{R}^{2}\right)$ values and the other models parameters. The data illustrated in table 3 , show that the adsorption isotherms agree well with Freundlish model for both (P1) and (P2) even at maximum adsorption capacity $\left(\mathrm{q}_{\mathrm{m}}\right)$. In the other hand, it does not verified by Termkin as well as Elovich model which confirm that interaction between dye and polyaniline is depending on physical binding with imines and amine groups on PANI surface. The values of $\mathrm{R}_{\mathrm{L}}$ lie between 0 and 1 , indicating that the adsorption is favorable. Also, the high linear regression $\left(\mathrm{R}^{2}\right)$ for Freundlish isotherm model indicates the heterogeneous and porosity of PANI surface especially for (P2) due to the formation of multilayers of adsorbed dye.

\section{Conclusion}

Polyaniline is proved to be a new promising adsorbent for Reactive (blue 19) dye. PANI prepared by hydrogen peroxide $\left(\mathrm{H}_{2} \mathrm{O}_{2}\right)$ in presence of ultrasonic waves and $\mathrm{FeCl}_{3}$ as catalyst has higher removal efficiency than PANI which was prepared by the classical chemical oxidation using APS initiator. The kinetics study revealed that the adsorption follows pseudo second order model where the equilibrium was achieved after $60 \mathrm{~min}$. The maximum adsorption capacity was $350 \mathrm{mg} / \mathrm{g}$ for PANI prepared by catalyzed hydrogen peroxide and $250 \mathrm{mg} / \mathrm{g}$ for PANI prepared by APS. Adsorption isotherms models revealed that the adsorption follows Freundlish model, which suggests physical sorption nature of interaction between PANI and reactive dye. 

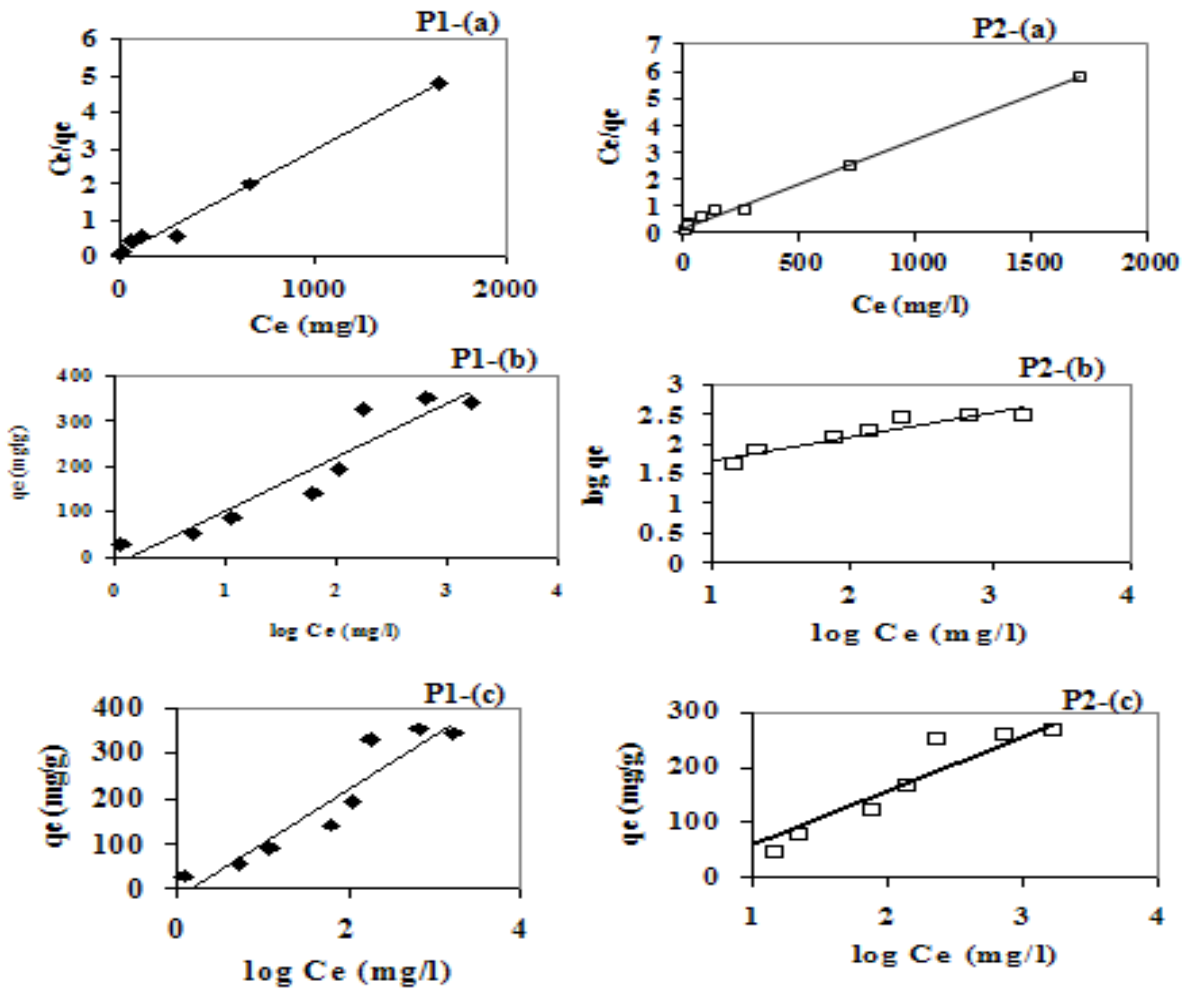

Fig. 8. Adsorption isotherm models of Blue 19 reactive dye onto PANI prepared by catalyzed $\mathrm{H}_{2} \mathrm{O}_{2}$ (P2) and APS (P1): (a) Langmuir, (b) Freundlich, (c) Termkin.

TABLE 3. Adsorption isotherms parameters for reactive (blue 19) dye adsorption on PANI prepared by different methods .

\begin{tabular}{|c|c|c|}
\hline & (P1) & (P2) \\
\hline \multicolumn{3}{|l|}{ Langmuir } \\
\hline$q_{m(\text { calc })}(\mathrm{mg} / \mathrm{g})$ & 303.03 & 370.143 \\
\hline$b(\mathrm{~L} / \mathrm{mg})$ & 0.0157 & 0.0333 \\
\hline$R_{L}$ & 0.11309 & 0.05673 \\
\hline$R^{2}$ & 0.902 & 0.92 \\
\hline \multicolumn{3}{|c|}{ Freundlich } \\
\hline$n$ & 2.81136 & 2.55885 \\
\hline$K_{\mathrm{F}}(\mathrm{mg} / \mathrm{g})$ & 31.952144 & 19.961814 \\
\hline$R^{2}$ & 0.964 & 0.982 \\
\hline \multicolumn{3}{|l|}{ Temkin } \\
\hline$A(\mathrm{~L} / \mathrm{g})$ & 23.49 & -36.4 \\
\hline$B$ & 117.4 & 91.31 \\
\hline$R^{2}$ & 0.6893 & 0.7258 \\
\hline
\end{tabular}

Egypt. J. Text. Polym. Sci. Technol. 14, No. 2 (2010) 


\section{References}

1. Skotheim, R., Elsenbaumer, R.L. and Reynolds, J.R., Handbook of Conducting Polymers, second ed., Marcel Dekker, New York, (1998).

2. Tejskal, J.S. and Gilbert, R.G., Polyaniline: Preparation of conducting polymer (IUPAC Technical Report), Pure Appl. Chem. J, 74, 857-867 (2002).

3. Tejskal, J.S. and Gilbert, R.G., Polyaniline: thin films and colloidal dispersion (IUPAC Technical Report), Pure Appl. Chem., 77, 815-826 (2005).

4. Chiang, J.C. and Mac-Diarmid, A.G., Polyaniline: Protonic acid doping of the emeraldine form to the metallic regime, Synthetic Metal, 13, 193-205 (1986).

5. Sambhu Bhadra, Dipak Khastgir, Nikhil, K. Singha and Joong Hee Lee , Progress in preparation, processing and applications of polyaniline, Progress in Polymer Science 34, 783-810 (2009).

6. Kang, E.T., Neoh, K.G. and Tan, K.L., Polyaniline: a polymer with many interesting intrinsic redox states, Progress in Polymer Science 23, 277-324 (1998).

7. Gospodinova, N. and Terlemezyan, L. Conducting polymers prepared by oxidative polymerization: (polyaniline), Progress in Polymer Science 23, 1443-1484 (1998).

8. Alan, G. and MacDiarmid, A., Novel Role for Organic Polymers (Nobel Lecture), Angew. Chem. Int. Ed. 40, 2581- 2590 (2001).

9. Nalwa, H.S., "Handbook of Organic Conductive Materials and Polymers", Wiley, New York, (1997).

10. Zaicheng Sun, Yanhou Geng, Ji. Li., Xiabin Jing and Fosong Wang, Chemical polymerization of aniline with hydrogen peroxide as oxidant, Synthetic Metals 84, 99100 (1997).

11. Abd El-Ghaffar, M.A. and Badawi, A., "Electrical Properties of Titanium and Germanium Doped Polyaniline" Proceeding of the 5th Arab International Conference on Polymer Science and Technology, Luxor-Aswan, Sept. 18-22, 3, 745-756 (1999).

12. Abd El-Ghaffar, M.A., Ashour, A.M. and Shafaai, K.H. Abbas, N.E.M., "Characterization and Electrical Properties of Hydrochloric Acid and Metal Doped Polyanilines" Egyptin J. of Text. and Polym. Sci. and Techn. 8, 77-96 (2004).

13. Abd El-Ghaffar, M.A., Youssef, E.A.M., Darwish, W.M. and Helaly, F.M., "A Novel Series of Corrosion Inhibitive Polymers For Steel Protection". J. Elastomers and Plastics, 30, 68-94 (1998).

14. Abd El-Ghaffar, M.A., "Plenary lecture entitled: New Trends in Corrosion Protection of Steel by Coatings, Overview on Some Novel Corrosion Inhibitive Pigments and Polymers" 27 $7^{\text {th }}$ Annual Conference: Corrosion Problems In Industry, Ismailia - Egypt, Nov. 26-28, (ECS) (2008). 
15. Abd El-Ghaffar, M.A., Nour El-Hoda, M., Abdel-Wahab and Youssef, E.A.M. "Polyaniline and poly(m-Toluidine) prepared by inverse emulsion pathway as corrosion inhibitors in surface coatings" Pigment \& Resin Technology, accepted for publication, vol.39, Issue 4, 228-236 (2010).

16. Ismail, M.N., Ibrahim, M.S. and Abd El-Ghaffar, M.A., "Polyaniline as Antioxidant and Antirad in SBR Vulcanizates" J. of Polymer Degradation and Stability, 62, 337-341 (1998).

17. Helaly, F.M., Darwich, W.M. and Abd El-Ghaffar, M.A., "Effect of Some Synthesized Polyamines on the Physico-mechanical Properties of NR and SBR Vulcanizates". J. of Polymer Degradation and Stability 64, 251-257 (1999).

18. Nour El-Hoda Abdel-Wahab and Abd El-Ghaffar, M.A. "Polyaniline hydrochloride for a novel application: accelerator and filler for phenol formaldehyde resin" Journal of Adhesion Science and Technology (accepted for publication, 2010).

19. Abd El-Ghaffar, M.A., Abou El Fettouh Abd El-Hakim and Ahmed M. Youssef., "Preparation and characterization of Polyaniline/Montmorillonite Nanocomposites Via In-situ Emulsion Polymerization Process "Synthetic metals (sent for publication, (2011).

20. Zaicheng Sun, Yanhou Geng, Ji, Li., Xiabin Jing and Fosong Wang., Catalytic Oxidization Polymerization of Aniline in an $\mathrm{H} 2 \mathrm{O} 2-\mathrm{Fe}+2$ System, J. of Applied Polymer Science 72, 1077-1084 (1999).

21. Sivakumar, M. and Aharon Gedanken, A., Sonochemical method for the synthesis of polyaniline and $\mathrm{Au}$-polyaniline composites using $\mathrm{H} 2 \mathrm{O} 2$ for enhancing rate and yield, Synthetic Metals 148, 301-306 (2005).

22. Donghua Zhang and Yangyong Wang., Synthesis and applications of onedimensional nano-structured polyaniline: An overview, Materials Science and Engineering B, 134, 9-19 (2006).

23. Raman Ganesan., Sangaraju Shanmugam and Aharon Gedanken, Pulsed sonoelectrochemical synthesis of polyaniline nanoparticles and their capacitance properties, Synthetic Metals, 158, 848-853 (2008).

24. Mahito Atobe., Al-Nakib Chowdhury. and Toshio Fuchigami., Tsutomu Nonaka., Preparation of conducting polyaniline colloids under ultrasonication, Ultrasonics Sonochemistry 10, 77-80 (2003).

25. Alexander Pud., Nikolay Ogurtsov., Alexander Korzhenko and Galina Shapoval, Some., aspects of preparation methods and properties of polyaniline blends and composites with organic polymers, Progress in Polymer Science 28, 1701-1753 (2003).

26. Lunhong, Ai., Jiang, J. and Rui Zhang., Uniform polyaniline microspheres: A novel adsorbent for dye removal from aqueous solution, Synthetic Metals 160, 762767 (2010). 
A COMPARATIVE STUDY FOR REACTIVE (BLUE 19) DYE ADSORPTION... 111

27. Potsangbam Albino Kumar, Saswati Chakraborty and Manabendra Ray., Removal and recovery of chromium from wastewater using short chain polyaniline synthesized on jute fiber," Chemical Engineering Journal 141, 130-140 (2008).

28. Erhan Demirbas, Mehmet Kobya, Elif Senturk and Tuncay Ozkan., Adsorption kinetics for the removal of chromium (VI) from aqueous solutions on the activated carbons prepared from agricultural wastes, Water SA 30 (2004).

29. Majid Riahi Samani, Sayed Mehdi Borghei, Ali Olad and Mohammad Javad Chaichi., Removal of chromium from aqueous solution using polyaniline - Poly ethylene glycol composite, J. Hazardous Materials 184, 248-254 (2010).

30. El-Naggar, I.M., Zakaria, E.S., Ali, I.M., Khalil, M. and El-Shahat, M.F., Kinetic modeling analysis for the removal of cesium ions from aqueous solutions using polyaniline titanotungstate, Arabian J. of Chemistry article in press (2010).

31. James, O. and Maloney, Perry's Chemical Engineering Handbook, $8^{T H}$ edition, McGraw Hill, New York (2008).

32. Anirudhan, T.S. and Radhakrishnan, P.G., " Chromium(III) removal from water and wastewater using a carboxylate functionalized cation exchanger prepared from a lignocellulosic residue, J. of Colloid and Interface Science 316, 268-276 (2007).

(Received 19/1/2011; accepted 20/11/2011) 


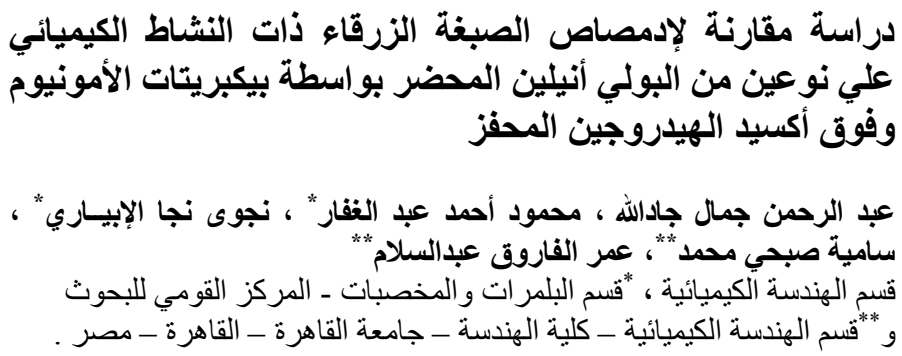

تهجف الدر اسة إلى إدمصاص الصبغة الزرقاء من النوع النشط (Reactive blue 19 )

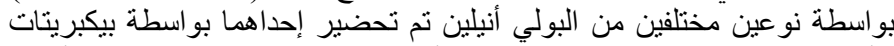

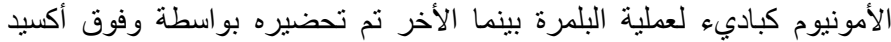

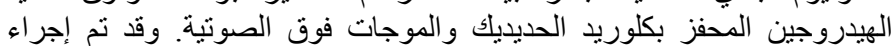
التجارب بتقليب البوليمر مع محلول الصبغة في تفاعل مغلق ( Batch mode)

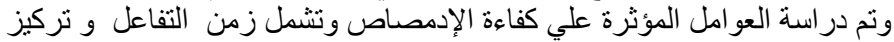

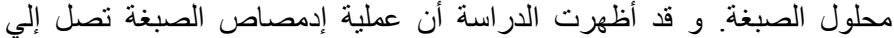

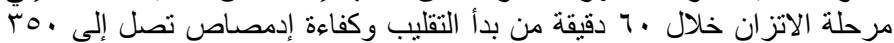

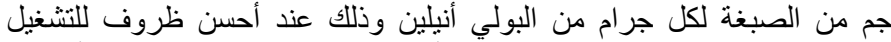

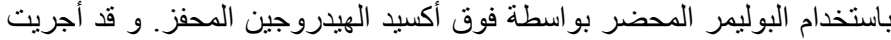

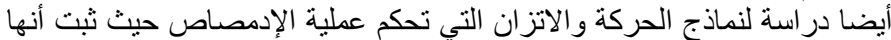

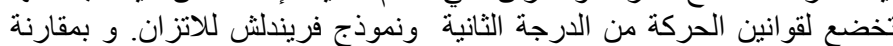

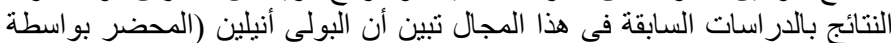

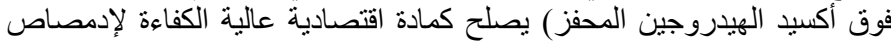
الصبغات الصناعية النشطة في معالجة مياه الصرف الصناف 